\title{
A importância do encorajamento de estudos sobre as doenças tropicais negligenciadas
}

\author{
Importance of encouragement of studies about neglected tropical diseases
}

\author{
Guilherme Malafaia ${ }^{1}$
}

\section{Prezado Editor:}

Venho por meio desta, parabenizar a Revista da Sociedade Brasileira de Medicina Tropical pela publicação da edição vol. 42, n. 2 de 2009 que trouxe uma gama de estudos sobre as principais doenças tropicais negligenciadas, apresentando relevante contribuição para 0 entendimento dos fenômenos biológicos e clínicos envolvidos nas infecções causadas pelos agentes etiológicos da esquistossomose, leishmaniose, malária e doença de Chagas. Sem dúvidas, sob o ponto de vista da produção científica esta edição mantém a indiscutível contribuição da Revista à divulgação de resultados relativos às "doenças tropicais negligenciadas", enfermidades prevalentes nas regiões tropicais, sobretudo, em países pobres, que proporcionam altos índices de morbi-mortalidade e gerar impactos sociais e econômicos negativos que afetam drasticamente a qualidade de vida das pessoas.

Conforme discutido recentemente por Hotez et $a l^{5}$, a esquistossomose, as leishmanioses e a doença de Chagas fazem parte do conjunto de doenças tropicais parasíticas mais negligenciadas. Enquanto cerca de 779 milhões de pessoas estão sob o risco de contrair a esquistossomose ${ }^{9}$, valores em torno de 350 e 25 milhões são estimados para o número de indivíduos sujeitos a contrair alguma das variantes das leishmanioses ${ }^{3}$ e a doença de Chagas $^{10}$, respectivamente.

Sobre a esquistossomose, destaca-se o trabalho de Lambertucci et $a l^{6}$, que ao apresentar imagens relacionadas à trombose da veia porta de um paciente com diagnóstico de esquistossomose mansônica hepatoesplênica, acabou por representar uma grande contribuição para a prática cirúrgica médica.

Quanto às leishmanioses, que de acordo com a Organização Mundial da Saúde (OMS) ${ }^{11}$, ocorrem em 88 países, sendo 72 destes, países em desenvolvimento, puderam-se observar importantes estudos no campo do conhecimento da sorologia em cães e gatos, da transmissão e da biologia dos vetores da leishmaniose tegumentar americana (ITA), que certamente

1. Curso de Pós-Graduação em Ciências Biológicas, Núcleo de Pesquisa em Ciências Biológicas, Laboratório de Doença de Chagas, Universidade Federal de Ouro Preto. Ouro Preto, MG.

Endereço para correspondência: Guilherme Malafaia. Rua Vereador Paulo Elias 8A, Vila Itacolomy, 35400-000 Ouro Preto, MG.

Tel: $55318696-5353$

e-mail: guilherme@nupeb.ufop.br

Recebido para publicação em 17/08/2009

Aceito em 03/09/2009 oferecem informações altamente pertinentes para o planejamento do controle da referida doença.

Com relação à malária, doença considerada a primeira causa de morte de crianças menores de 5 anos na África, e que mata uma criança a cada 30 segundos no mundo ${ }^{4}$, o estudo de Muniz-Junqueira $e t a l$, ao apresentar uma avaliação microscópica dos estágios da fagocitose in vitro de eritrócitos infectados por Plasmodium falciparum, mostrou importantes dados relacionados aos aspectos celulares envolvidos no controle da infecção, os quais podem subsidiar estudos posteriores in vivo.

Já sobre a doença de Chagas, considerada uma das doenças mais negligenciadas, destacam-se os estudos de Borges $e t a{ }^{2}$, Scapellato $e t a l^{\beta}$ e Almeida $e t a l^{1}$. Suas contribuições referemse ao melhor entendimento sobre o papel do óxido nítrico (NO) no controle do parasitismo pelas cepas Y e Colombiana do Trypanosoma cruzi durante a fase aguda na doença de Chagas experimental ${ }^{2}$; à constatação de que a co-infecção Trypanosoma cruzi e vírus HIV" pode aumentar significativamente 0 risco de transmissão vertical da doença de Chagas $^{8}$ e ao relato de um caso de co-infecção "Trypanosoma cruzi e vírus HIV”, o qual tem importantes implicações na prática médica ${ }^{1}$.

A doença de Chagas, em particular, considerada uma das patologias de mais larga distribuição no continente americano, completa em 2009 cem anos de seu descobrimento. No entanto, muitos aspectos relacionados à referida enfermidade ainda carecem de esclarecimentos. A doença apresenta importantes aspectos sócioculturais e político-econômicos que envolvem questões de iniquidade e globalização, que muitas vezes não são considerados. Além disso, a ausência de progressos na etiopatogenia (os quais elucidariam os mecanismos pelos quais o parasito lesa o organismo), na quimioterapia (os quais permitiriam o desenvolvimento de medicamentos aptos a eliminar eficientemente o protozoário etiológico) e na sorologia (os quais possibilitariam o desenvolvimento de técnicas ou provas sorológicas mais confiáveis), constitui um dos grandes desafios a serem superados. Isso sem falar que o desenvolvimento de uma vacina contra a doença ainda é considerado algo incipiente e que não há, ainda, uma forma de prevenir a transmissão do parasito por via congênita, sendo consenso que, para esta modalidade, a melhor estratégia seja a detecção precoce do caso e seu pronto tratamento.

Gostaria de finalizar destacando que, no âmbito nacional, poucas são as revistas bem qualificadas que atualmente 
contribuem significativamente com a disseminação da produção científica de artigos de saúde pública acerca das doenças tropicais negligenciadas. Portanto, ao divulgar trabalhos sobre temas relacionados à malária, leishmanioses, esquistossomose e doença de Chagas, a Revista não apenas faz jus ao seu compromisso de divulgar dados relevantes para saúde pública, como também contribui para aumentar as opções de disseminação de informação científica sobre estas doenças tão negligenciadas.

\section{REFERÊNCIAS}

1. Almeida EA, Silva EL, Guariento ME, Souza ML, Aoki FH, Pedro RJ. Evolução fatal da co-infecção doença de Chagas/Aids: dificuldades diagnósticas entre a reagudização da miocardite e a miocardiopatia chagásica crônica. Revista da Sociedade Brasileira de Medicina Tropical 42: 199-202, 2009.

2. Borges CRB, Rodrigues-Junior V, Reis MA, Castellano LR, Chica JEL, Pereira SAL, Santos ES, Rodrigues DBR. Papel do óxido nítrico no desenvolvimento de lesões cardíacas na fase aguda da infecção experimental pelo Trypanosoma cruzi. Revista da Sociedade Brasileira de Medicina Tropical 42: 170-174, 2009.

3. Desjeux P. Leishmaniasis: current situation and new perspectives. Comparative Immunology Microbiology \& Infectious Disease 27: 305-318, 2004.
4. Drugs for Neglected Diseases initiative (DNDi). Doenças Negligenciadas - Malária. Disponível em: http://www.dndi.org.br/Portugues/malaria.aspx. Acesso em 6 de agosto de 2009.

5. Hotez PJ, Molyneux DH, Fenwick A, Kumaresan J, Sachs SE, Sachs JD, Savioli L. Control of neglected tropical diseases. The New England Journal of Medicine 357:1018-1027, 2007

6. Lambertucci JR, Resende V, Voieta I. Trombose da veia porta em paciente com esquistossomose mansônica hepatoesplênica. Revista da Sociedade Brasileira de Medicina Tropical 42: 235-236, 2009.

7. Muniz-Junqueira MI, Tosta CE. Carlos Eduardo. Estágios da fagocitose in vitro por monócitos humanos de eritrócitos infectados por Plasmodium falciparum. Revista da Sociedade Brasileira de Medicina Tropical 42: 103-106, 2009.

8. Scapellato PG, Bottaro EG, Rodriguez-Brieschke MT. Transmissão materno-fetal da doença de Chagas: poderia a co-infecção com vírus da imunodeficiência humana aumentar o risco? Revista da Sociedade Brasileira de Medicina Tropical 42: 107-109, 2009.

9. Steinmann P, Keiser J, Bos R, Tanner M, Utzinger J. Schistosomiasis and water resources development: systematic review, meta-analysis, and estimates of people at risk. The Lancet Infectious Diseases 6:411-425, 2006.

10. World Health Organization (WHO). Expert Committee. Control of Chagas disease. Geneva, World Health Organ Tech Rep Ser, 2002.

11. World Health Organization (WHO). Program for the surveillance and control of leishmaniasis. Geneva, World Health Organization, 2005. 